\title{
Pial Arteriovenous Fistulas Associated with Multiple Aneurysms Presenting as Intracerebral Hemorrhage: A Case Report
}

\author{
Intraserebral Kanama Olarak Ortaya Çıkan Çoklu Anevrizmalar ile \\ İlişkili Pial Arteriyovenöz Fistüller: Bir Olgu Sunumu
}

\author{
Wu CAI ${ }^{1}$, Jianping $\mathrm{GONG}^{1}$, Bochao $\mathrm{CHENG}^{2}$, Fang $\mathrm{QIAO}^{1}$, Wei ZHANG ${ }^{1}$, Qing $\mathrm{ZHU}^{3}$, Qing $\mathrm{LAN}^{3}$ \\ ${ }_{1}^{1}$ Second Affiliated Hospital of Soochow University, Department of Radiology, Suzhou, P.R. China \\ ${ }^{2}$ West China Hospital of Sichuan University, Department of Radiology, Chengdu, P.R. China \\ ${ }^{3}$ Second Affiliated Hospital of Soochow University, Department of Neurosurgery, Suzhou, P.R. China
}

Corresponding Author: Jianping GONG / E-mail: gongjianpingsz@126.com

\begin{abstract}
Intracranial pial arteriovenous fistulas (AVFs) associated with multiple aneurysms of the main feeding arteries are very rare cerebrovascular lesions. We report a unique case of pial AVFs associated with four aneurysms of the feeding anterior cerebral artery (ACA) which presented as intracerebral hemorrhage $(\mathrm{ICH})$, intraventricular hemorrhage (IVH) and spontaneous subarachnoid hemorrhage (SAH). CT angiography (CTA) and digital subtraction angiography (DSA) images demonstrated clearly the direct connection without nidus between the first and second segment of right ACA accompanied by four irregular aneurysms and an abnormally dilated draining vein into the superior sagittal sinus (SSS). Owing to the superficial-seated fistulas, the morphology of feeding arteries and associated four aneurysms and intracranial hemorrhage, the lesions were surgically treated. Postoperative cerebral angiography certified closure of the fistulas and exclusion of the four aneurysms as well as disappearance of early venous drainage. However, subsequent precontrast brain CT showed hydrocephalus underwent left ventriculoperitoneal shunt placement.
\end{abstract}

KEYWORDS: Pial arteriovenous fistula, Aneurysm, Cerebral hemorrhage, Angiography, Surgery

öz

Ana besleyici arterlerin birden fazla anevrizması ile ilişkili intrakraniyal pial arteriyovenöz fistüller (AVF'ler) çok nadir serebrovasküler lezyonlardır. Burada intraserebral kanama (ISK), intraventriküler kanama (IVK) ve spontan subaraknoid kanama (SAK) olarak ortaya çıkan, anterior serebral arterin (ASA) dört anevrizması ile ilişkili benzersiz bir pial AVF olgusu bildiriyoruz. BT anjiyografi (BTA) ve dijital subtraksiyon anjiyografi (DSA) görüntüleri net bir şekilde dört düzensiz anevrizmanın eşlik ettiği, sağ ASA'nın birinci ve ikinci segmenti arasında nidus olmaksızın doğrudan bağlantıyı ve superior sagittal sinüs (SSS) içine anormal genişlemiş drenaj venini göstermiştir. Yüzeysel yerleşimli fistüller, besleyici arterler, ilgili dört anevrizma ve intrakraniyal kanama morfolojisi nedeniyle lezyonlar cerrahi olarak tedavi edildi. Postoperatif serebral anjiyografi hem fistüllerin kapatılması ve dört anevrizmanın eksklüzyonunu hem de erken venöz drenajın ortadan kaldırılmasını doğruladı. Ancak, sonraki prekontrast beyin BT hidrosefali gösterdi ve sola ventriküloperitoneal şant uygulandı.

ANAHTAR SÖZCÜKLER: Pial arteriyovenöz fistül, Anevrizma, Beyin kanaması, Anjiyografi, Cerrahi

\section{INTRODUCTION}

Intracranial pial arteriovenous fistulas (AVFs) have been differentiated from arteriovenous malformations (AVMs) for lack of the nidus, which occur in $1.6 \%$ to $2.4 \%$ of all brain AVMs $(2,5,14)$. We present an unusual case of pial AVFs associated with multiple aneurysms of the main feeding arteries and intracerebral hemorrhage $(\mathrm{ICH})$, intraventricular hemorrhage (IVH) and spontaneous subarachnoid hemorrhage (SAH), which can be illustrated by CT angiography (CTA) and digital subtraction angiography (DSA) and treated surgically, and to review the relevant literature.

\section{CASE REPORT}

\section{History and Presentation}

A 42-year-old man came to our hospital for headache that lasted one week, accompanied by nausea and vomiting. His initial Glasgow coma scale score was 15 (E4V5M6). His headache suddenly aggravated in addition to becoming unconscious and brain CT scanning examined with a 64row multidetector CT system (GE LightSpeed VCT; GE Healthcare Technologies, Milwaukee, WI, USA) immediately after admission. No history of obvious head trauma and mucocutaneous telangiectasia was found. None of his family members including siblings and parents suffered from such disease. The $\mathrm{CT}$ demonstrated $\mathrm{ICH}$ surrounded by brain 
edema in the right frontal lobe, IVH in the third, fourth and bilateral lateral ventricles and $\mathrm{SAH}$ in the interhemispheric cistern and bilateral cistern of lateral sulcus (Figure 1A). Threedimensional CTA (3D-CTA) showed the intracranial pial AVFs in the right anterior cranial fossa, which were mainly supplied by two branches originated from the first and second segment junction and the proximal section of the second segment of right anterior cerebral artery (ACA) and drained into the superior sagittal sinus (SSS) through an abnormally dilated and tortuous draining vein. The two feeding arteries also presented four irregular aneurysms and the proximal section of the second segment aneurysm was the most irregular and largest one (Figure 1B, C). The preoperative conventional DSA and $3 \mathrm{D}$ rotational angiography were undertaken (Allura Xper FD20; Philips Medical Systems, Netherlands) to confirm the findings of 3D-CTA revealing the direct connection without nidus between the first and second segment of right ACA accompanied by four irregular aneurysms and an abnormally dilated draining vein into the SSS. There were also many disordered and small vessels as well as the abnormally draining vein in the late arterial phase in the right anterior cranial fossa (Figure 1D-F).

\section{Surgical Treatment}

According to the 3D-CTA and DSA findings, the patient received surgical therapy. Under the general anesthesia, the coronary incision was first performed from the left frontal to right frontotemporal region. Cranial drilling was performed and dura mater was cut open so that the left frontal horn of lateral ventricle puncture and drainage were executed successfully. The right frontotemporal craniotomy was performed, and the sphenoid ridge lateral and anterior skull base inner plate were stripped. The cerebral dura mater and arachnoid were then cut out to expose SAH absorbed completely. Once the right internal carotid artery (ICA) had been recognized, its course to ipsilateral ACA was checked until the two main feeding arterial branches originated from the first and second segment junction and the proximal section of the second segment of the ACA coupled with four irregular aneurysms were visualized. Following the two main feeding arterial branches of the ACA, the neck of the proximal two irregular aneurysms of the feeding arteries were clipped; subsequently, the body of the two aneurysms and the distal feeding arteries including another two distal aneurysms were electrically coagulated, cauterized and cut in order to close the main fistulous connection and aneurysms of the ACA. The proximal section of the second segment aneurysm was the largest and responsible one, whose top was congested, thinned and adherent to the right frontal lobe haematoma which was removed meanwhile. Lastly, the draining vein was closed.

\section{Postoperative Course}

The postoperative cerebral angiography certified exclusion of the four aneurysms including two clipped and closure of the fistulas as well as disappearance of early venous drainage (Figure 1G-I). However, subsequent precontrast brain CT showed hydrocephalus but no hemorrhage, which was underwent left ventriculoperitoneal shunt placement. At two months after surgery, the patient is follow-up with neurologically intact and clinical stable.

\section{DISCUSSION}

Intracranial pial AVFs are composed of one or more direct arterial shunt to a sole venous channel without abnormal interconnecting nidus, which differentiate from AVMs for the absence of nidus and dural AVFs for the feeding vessels originated from pial or cortical arteries and located outside of the dural leaflets $(4,12)$. The high and turbulent blood flow hemodynamics of pial AVFs result from arteriovenous shunt from feeding arteries directly into single draining vein, which result in venous dilatation, varix and even the aneurysm of the feeding artery $(8,10)$. The associated four aneurysms of the feeding ACA in this case are produced by its high-flow nature. Owing to the existence of the fistulas, the blood flow of main feeding arteries especially the site of turning and bifurcation increase significantly, which induce the blood flow overloaded and the formation of aneurysms. The cause of pial AVFs can be traumatic, iatrogenic or congenital. The most common in adult is traumatic carotid cavernous fistula. Congenital pial AVFs often happen in child; however, many patients aren't diagnosed until they have clinical symptoms and signs such as hemorrhage, headache and increased intracranial pressure in adults like this case $(1,8,10)$. The exact etiology of pial AVFs is still not clear. The pathophysiologic mechanisms may be a misstep in embryological development of the cerebrovasculature or abnormal angiogenesis and associated vascular growth factors and cytokine (3). Some reports indicate an association with genetic syndromes such as Rendu-Osler-Weber (hereditary hemorrhagic telangiectasia), phosphatase and tensin homolog hamartomatous tumor, Klippel-Trenaunay-Weber, neurofibromatosis, Sturge-Weber and Ehlers-Danlos (2, 9-10). Paramasivam et al (9) have reported a patient had a family history of AVM and pinkish red multiple cutaneous capillary malformation of varying sizes involving the trunk suggestive of RASA1 mutation causing capillary malformation-AVM. However, there is no genetic syndrome and family history of vascular disease in this case.

3D-CTA and DSA are the main tools for diagnosis of the pial AVF. 3D-CTA not only can show the direct connection between the feeding artery and draining vein in unlimited projections, but also can delineate the 3D spatial relationship with adjacent structures. However, DSA especially 3D rotational angiography is the current gold standard for the detection and characterization of the pial AVF, which can illustrate the complicated angioarchitecture clearly due to its intrinsic capability of acquiring images at any angles (8). Furthermore, it can dynamically identify the blood flow direction, and meanwhile, the lesions can be directly received endovascular treatment. The feeders from the first and second segment of right ACA accompanied by four irregular aneurysms and abnormally dilated draining vein into the SSS were delineated clearly on 3D-CTA and DSA angiograms in this case. There 

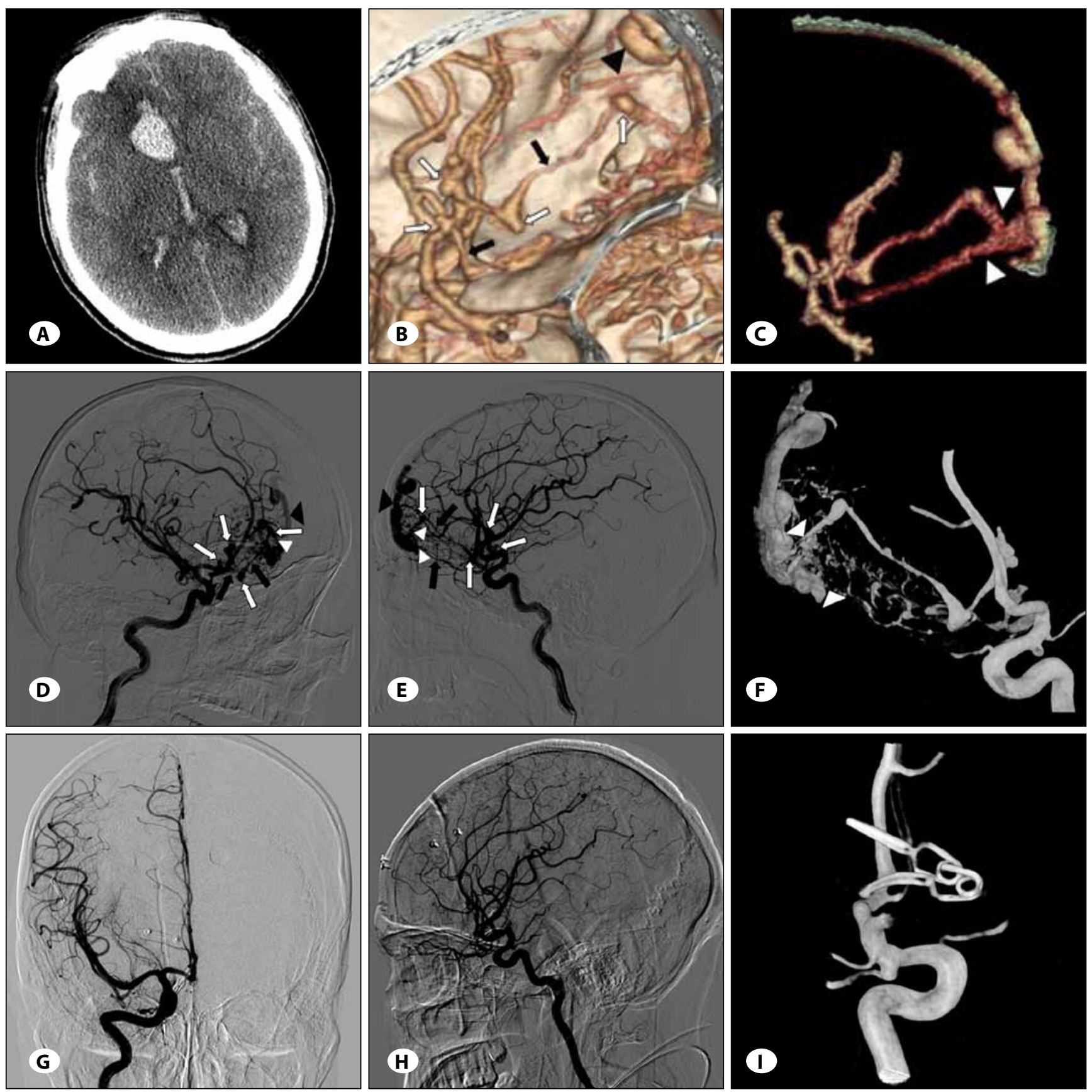

Figure 1: A 42-year-old man with pial AVFs accompanied by multiple aneurysms of the main feeding arteries. A) Initial precontrast brain CT scan demonstrating intracerebral hemorrhage in the right frontal lobe, intraventricular hemorrhage in the third ventricle and bilateral lateral ventricles and spontaneous subarachnoid hemorrhage in the interhemispheric cistern and bilateral cistern of lateral sulcus. B) 3D-CTA without bone subtraction image showing direct connection between two branches (black arrows) originated from the first and second segment of right ACA accompanied by four irregular aneurysms (white arrows) and drained into the superior sagittal sinus through an abnormally dilated and tortuous draining vein (black arrowhead). C) 3D-CTA with bone subtraction image not only revealing the main feeding arteries associated with aneurysms and draining vein, but also delineating clearly the fistulas (white arrowheads). Right D) and left E) lateral conventional DSA images illustrating the pial AVF between the two feeding arterial branches (black arrows) of right ACA accompanied by four aneurysms (white arrows) and an abnormally dilated and tortuous draining vein (black arrowhead) drained into the superior sagittal sinus. The fistulas (white arrowheads) and many disordered and small vessels in the anterior cranial fossa were also depicted clearly. F) 3D rotational angiography image showing the pial AVF coupled with four aneuryms, especially the fistulas (white arrowheads) more clearly than conventional DSA for its inherent capability of acquiring 3D reconstruction images at any angles. Postoperative anteroposterior $\mathbf{G})$, left lateral $\mathbf{H}$ ) and 3D rotational angiography images I) revealing complete disappearance of all vascular lesions including two of four aneurysms clipped, fistulas, dilated and tortuous draining vein into superior sagittal sinus and many disordered and small vessels in the anterior cranial fossa. 
have been several reports describing one or two aneurysms of the feeding artery $(1,10-11)$. However, intracranial pial AVFs associated with four irregular aneurysms of the feeders presenting as $\mathrm{ICH}, \mathrm{IVH}$ and $\mathrm{SAH}$ as in this case have never reported before.

The therapy strategy of intracranial pial AVFs even when asymptomatic is disconnection of the arteriovenous shunt due to the potential fatal cerebral hemorrhage, worse neurocognitive prognosis and especially high mortality after conservative management (7). The treatment modality for obliterating the fistula can be successfully acquired by endovascular embolization or surgery. Recently, the rapid development of endovascular embolization, which is less invasive and allows direct localization of the lesions, makes it the preferred therapy modality. Large numbers of embolic agents such as balloons, coils, glue, Onyx and NCBA have been used for the successful occlusion of the fistula $(9,15)$. However, there was a review reported by Yang et al (13), surgery had a higher obliteration rate $(96.8 \%)$ than endovascular embolization (86.5\%). However, we should pay more attention to the indication for surgery was only for selected superficial fistulas.

In our case, surgical management was executed for the following reasons. Firstly, the two feeding arterial diameters were small and the shape of associated four aneurysms were irregular, which were unfavorable for endovascular treatment for their morphology. Furthermore, superficial-seated fistulas could be easily reach via right frontotemporal craniotomy and an exposure of SSS. Last but not the least, the right frontal lobe haematoma must be removed, meanwhile, the $\mathrm{SAH}$ should be absorbed and IVH should be drained. The goal of surgery is the obliteration of fistulas and the closure of draining vein (10). The proximal two irregular aneurysms were directly clipped and the distal feeding arteries including another distal two aneurysms were obliterated during the same surgical treatment. Meantime, the ICH, IVH and SAH were handled. One-month follow-up cerebral angiography showed the fistulas were entirely occluded and exclusion of the four aneurysms and disappearance of early venous drainage. However, precontrast CT scan demonstrated the complication of hydrocephalus, which may have resulted from thrombosis of the draining veins initially arterialized (6). Heparin should therefore be given appropriately after surgery.

In conclusion, this case illustrated an extremely rare presentation of pial AVFs associated with four aneurysms of the main feeding arteries of right ACA and drained into SSS through an abnormally dilated and tortuous draining vein. Pial AVFs were characterized by high flow essence, which resulted in the rupture of the largest associated aneurysm presented as $\mathrm{ICH}, \mathrm{IVH}$ and $\mathrm{SAH}$ and all the lesions were successfully surgically treated. Hydrocephalus due to venous thrombosis may emerge as the main complication, and heparin should be given appropriately after surgery.

\section{REFERENCES}

1. Carrillo R, Carreira LM, Prada J, Rosas C, Egas G: Giant aneurysm arising from a single arteriovenous fistula in a child. Case report. J Neurosurg 60:1085-1088, 1984

2. Halbach VV, Higashida RT, Hieshima GB, Hardin CW, Dowd CF, Barnwell SL: Transarterial occlusion of solitary intracerebral arteriovenous fistulas. AJNR Am J Neuroradiol 10:747-752, 1989

3. Hoh BL, Putman CM, Budzik RF, Ogilvy CS: Surgical and endovascular flow disconnection of intracranial pial singlechannel arteriovenous fistulae. Neurosurgery 49:1351-1363; discussion 1363-1364, 2001

4. Kikuchi K, Kowada M, Sasajima H: Vascular malformations of the brain in hereditary hemorrhagic telangiectasia (RenduOsler-Weber disease). Surg Neurol 41:374-380, 1994

5. Lasjaunias $P$, Manelfe $C$, Chiu M: Angiographic architecture of intracranial vascular malformations and fistulas: Pretherapeutic aspects. Neurosurg Rev 9:253-263, 1986

6. Lv X, Jiang C, Li Y, Yang X, Wu Z: Clinical outcomes of endovascular treatment for intracranial pial arteriovenous fistulas. World Neurosurg 73:385-390, 2010

7. Nelson K, Nimi Y, Lasjaunias P, Berenstein A: Endovascular embolization of congenital intracranial pial arteriovenous fistulas. Neuroimaging Clin N Am 2:309-317, 1992

8. Oh HJ, Yoon SM, Kim SH, Shim JJ: A case of pial arteriovenous fistula with giant venous aneurysm and multiple varices treated with coil embolization. J Korean Neurosurg Soc 50:248-251, 2011

9. Paramasivam S, Toma N, Niimi Y, Berenstein A: Development, clinical presentation and endovascular management of congenital intracranial pial arteriovenous fistulas. J Neurointerv Surg 5:184-190, 2013

10. Passacantilli E, Pichierri A, Guidetti G, Santoro A, Delfini R: Surgical treatment of pial cerebellar arteriovenous fistulas with aneurysm of the main feeding artery. Surgical Neurology 65:90-94, 2006

11. Ratliff J, Voorhies RM: Arteriovenous fistula with associated aneurysms coexisting with dural arteriovenous malformation of the anterior inferior falx: Case report and review of the literature. J Neurosurg 91:303-307, 1999

12. Santosh C, Teasdale E, Molyneux A: Spontaneous closure of an intracranial middle cerebral arteriovenous fistula. Neuroradiology 33:65-66, 1991

13. Yang WH, Lu MS, Cheng YK, Wang TC: Pial arteriovenous fistula: A review of literature. Br J Neurosurg 25:580-585, 2011

14. Yasargil MG: Microneurosurgery. vol. IIIB. Stuttgart: Georg Thieme Verlag, 1993:358-361

15. Zhang Z, Yang K, Wang C, Zhang C, Xie X, Tang J: Congenital pial arteriovenous fistula in the temporal region draining into cavernous sinus: A case report. Korean J Radiol 14:497-500, 2013 